\title{
Interspecific competition limits larders of pygmy owls Glaucidium passerinum
}

\author{
Jukka Suhonen, Matti Halonen, Tapio Mappes and Erkki Korpimäki \\ J. Suhonen (correspondence), M. Halonen and T. Mappes, Dept. of Biological and Environmental Science, P.O. Box 35, FIN-40014 \\ University of Jyväskylä, Finland. Present address of J. Suhonen: Section of Ecology, Dept. of Biology, University of Turku, FIN-20014 \\ Turku, Finland, E-mail: juksub@utu.fi. - E. Korpimäki, Section of Ecology, Dept. of Biology, University of Turku, FIN-20014 \\ Turku, Finland.
}

\begin{abstract}
To test whether competitive and predatory interactions limit larder size we erected pygmy owl Glaucidium passerinum nest-boxes for hoarding with $45 \mathrm{~mm}$ entrance diameter near and far $(>2 \mathrm{~km})$ from Tengmalm's owl Aegolius funereus nest-boxes with $>80 \mathrm{~mm}$ entrance diameter during early autumn. We found larders of pygmy owls in similar frequency in both near and far plots ( 41 vs. $42 \%$ of plots), but in near plots the number and biomass of cached prey by pygmy owls were lower. These results suggest that there is competition for food between these two owl species and/or that food caching behaviour of pygmy owls is disturbed by larger Tengmalm's owls.
\end{abstract}

Interactions among species, such as competition and predation, are fundamental biotic factors determining population densities of animals (Sih et al. 1985, Gurevitch et al. 2000). Frequently the competitive effects are asymmetric, with one of the interacting species being more affected than the other (Connell 1983, Schoener 1983, Persson 1985, Wiens 1989). Predation has more direct fitness effects than competition (Lima and Dill 1990), and has also been considered to have at least similar or even larger effects on animal communities than competition (Sih et al. 1985, Gurevitch et al. 2000). In vertebrate predators, intra-guild predation is usually size-determined with larger species preying on smaller one (Korpimäki and Norrdahl 1989a, Polis and Holt 1992, Hakkarainen and Korpimäki 1996, Palomares and Caro 1999). In these conditions, the smaller species may enhance coexistence with its predator by resource partitioning and spatial avoidance (Korpimäki and Norrdahl 1989a, Polis et al. 1989, Hakkarainen and Korpimäki 1996, Sergio et al. 2003). There also is experimental evidence that competitive and predatory interactions among birds of prey can reduce the reproductive success of smaller species involved (Hakkarainen and Korpimäki
1996, Krüger 2002), but experimental studies on competitive and predatory interactions between two bird of prey species during non-breeding season are missing.

This study was aimed to examine whether competitive and predatory interactions by larger owl species affect the size of larders of pygmy owls Glaucidium passerinum during winter. Pygmy and Tengmalm's owls Aegolius funereus coexist in North and Central European coniferous forests (Schönn 1980, Korpimäki 1981, Mikkola 1983). These two owl species are the only common birds of prey which prey on small mammals and passerine birds in our study region in winter and they have broadly overlapping diets (e.g. Kellomäki 1977, Korpimäki 1981, 1988a, Mikkola 1983, Suhonen 1993, Kullberg 1995). Pygmy owls cache small mammals and birds in holes and nest-boxes during late autumn and winter (Kellomäki 1977, Solheim 1984, Ekman 1986, Suhonen 1993, Halonen et al. 2007). Larder contents vary greatly with the availability of voles (Kellomäki 1977, Solheim 1984, Suhonen 1993, but see Ekman 1986). Adult male Tengmalm's owls occupy their territories throughout the year after the first breeding attempt, apparently guarding their nest-holes against 
competitors (Korpimäki 1988b, 1993). Tengmalm's owls can sometimes even kill pygmy owls (Schönn 1980, Mikkola 1983).

\section{Materials and methods}

The study was carried out during the two winters 1990-1991 and 1991-1992 in the Kauhava region $\left(63^{\circ} \mathrm{N}, 23^{\circ} \mathrm{E}\right)$, western Finland. This area consists of coniferous forests with high proportions of agricultural land and some peatland bogs (Korpimäki 1981, 1987, 1988b, Hakkarainen et al. 2003). During the first winter we established nine near and seven far plots, and during the second winter ten near and ten far plots. During the second winter, both the near and far plots were relocated more than $2 \mathrm{~km}$ from the near and far plots of first winter to avoid that the same owl individuals would have used the same nest-boxes for caching in two winters. In each near and far plots, we provided two boxes for pygmy owls as larder sites. The boxes had an entrance hole ( $45 \mathrm{~mm}$ in diameter) that was too small to be used by any other birds of prey (Solheim 1984). Distance between these two boxes within a plot was 50 to $100 \mathrm{~m}$ and the distance between two different plots was $>1 \mathrm{~km}$. In the near plots, the pygmy owl nest-boxes were erected within $100 \mathrm{~m}$ of a Tengmalm's owl nest-box, which had an entrance $>80 \mathrm{~mm}$ in diameter. Wintering Tengmalm's owls use these nest-boxes for roosting (Korpimäki 1981). The near plots were located within a large $\left(1,300 \mathrm{~km}^{2}\right)$ long-term study area of Tengmalm's owls where the density of nest-boxes with large-entrance $(>80 \mathrm{~mm})$ was $0.5-1.0$ per $\mathrm{km}^{2}$ (Korpimäki 1981, 1988a,b, Hakkarainen et al. 2003). The percentage of nest-boxes inhabited by Tengmalm's owls during the breeding season was $23 \%$ in spring 1991 and $33 \%$ in spring 1992 (Korpimäki 1994). The density of wintering Tengmalm's owls was high, because the majority of males stay in their breeding territory over the winter (Korpimäki 1988b, 1993). The far plots were $>2 \mathrm{~km}$ from the nearest Tengmalm's owl nest-box or natural cavity with large entrance, and therefore density of wintering Tengmalm's owls probably was lower than in near plots.

Near and far plots were situated in managed coniferous forests where deciduous trees and natural cavities were scarce. Therefore, all Tengmalm's owls bred in nest-boxes. On the basis of several criteria, we chose the study plots as similar as possible. We used the proportions of main habitat types measured on landscape maps and also recorded in the field within $500 \mathrm{~m}$ of each near and far plots as indicators of similarity. Because voles are the main prey species of pygmy and Tengmalm's owls, small mammal abundance was estimated by snap-trapping in mid-September in four sample plots in the western and eastern parts of the Tengmalm's owl study area. Sample plots were in each of the main habitat types and were at least $2 \mathrm{~km}$ of pygmy owl nest-boxes used in this study (see Korpimäki and Norrdahl 1989b for further details on the methods).

Prey items cached by pygmy owls in boxes of near and far plots were checked on one day once a month from late October to early March. Prey items were identified to the species and were weighed with a Pesola spring balance to the nearest $1.0 \mathrm{~g}$. To avoid counting any stored prey item twice, all items were marked individually, birds with plastic colour rings and small mammals by toe clipping. The number of cached prey items and their biomass were pooled for both nestboxes in a plot. These pooled data per plot were used as independent observations for statistical testing.

We examined possible differences in numbers of cached prey items and total biomass of cached prey items by two-way ANOVAs. The treatment was introduced as fixed factor and year as random factor. Number of cached prey items and biomass of larder were $\log _{10}$-transformed in the two-way ANOVA. We did not calculate interaction term in the two-way ANOVAs because sample size was only one in the first winter in experiment plots (Fig. 1). We used the Mann-Whitney U test to find the differences in habitat variables, different prey groups and number of consumed prey items between control and experimental plots. We conducted all analyses in SPSS (version 12.0.1).

\section{Results}

Caches of pygmy owls in small-entrance nest-boxes were found in both the far and near plots ( $41 \%$ vs. $42 \%$ of plots, respectively; Table 1) with no difference in occurrence $\left(\chi^{2}=0.003, \mathrm{df}=1, \mathrm{P}=0.96\right)$. In contrast, pygmy owls did not cache prey items in large-entrance nest-boxes in the near plots. During the first winter, when the vole density was lower (pooled number of Microtus and bank voles Cletrionomys glareolus 9.9 per 100 trap-nights), only one larder was found in near plot (Fig. 1). In the second winter, when vole numbers had increased to 21.9 individuals per 100 trap-nights, six near plots contained larders (Fig. 1).

In the near plots the larders contained one to nine prey items, except in one plot, where a pygmy owl cached 42 voles in one plot. In each of the far plots, the larders of pygmy owls contained more prey items (twoway ANOVA, $\mathrm{F}_{1,12}=14.10, \mathrm{P}=0.003$; Fig. 1 ). The total biomass of cached prey items in the plots was significantly higher in the far than near plots (mean $=$ $700 \mathrm{~g}, \mathrm{SD}=380 \mathrm{~g}$ vs. mean $210 \mathrm{~g}, \mathrm{SD}=330 \mathrm{~g}$; two-way ANOVA, $\left.\mathrm{F}_{1,12}=10.68, \mathrm{P}=0.007\right)$. However, the 


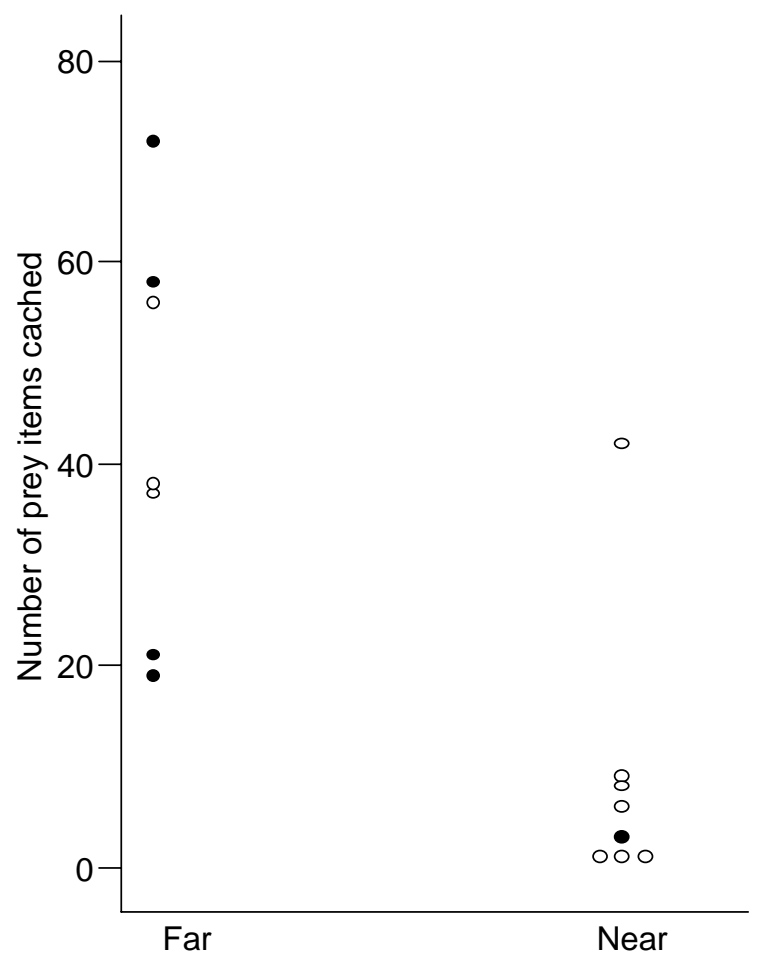

Fig. 1. Number of prey items in larders of pygmy owls in each far from Tengmalm's owl nest-boxes (Far) and in the vicinity of Tengmalm's owl nest-boxes (near) plots. Filled dots denote winter 1990-1991 and open dots denote the winter 1991-1992.

between-year difference was not statistically significant in the number of cached prey items $\left(\mathrm{F}_{1,12}=0.11, \mathrm{P}=\right.$ $0.75)$, nor in total biomass $\left(\mathrm{F}_{1,12}=0.72, \mathrm{P}=0.41\right)$.

In every prey group, the mean number of cached prey items was higher in the far plots than in the near plots, but the difference was statistically significant for bank voles and shrews (Sorex spp.) only (Table 1). Also, the number of cached prey items consumed during winter was slightly larger in the far plots than in the near plots (mean $=20.0, S D=12.0$ vs. mean $=5.1$, $\mathrm{SD}=10.3 ; \mathrm{U}=11.5, \mathrm{P}=0.054)$.

We measured the percent cover of five main habitat types in near and far plots: pine Pinus sylvestris dominated forests (mean (SD) percent cover in near plots 59\% (11, number of plots 19) and in far plots $52 \%(17, \mathrm{n}=17))$, spruce Picea abies dominated forests (8\% (7) vs. $8 \%(12))$, peatland bogs (mostly pinedominated bogs $16 \%$ (10) vs. $20 \%$ (14), agricultural fields $[16 \%(10)$ vs. $16 \%(12))$, and lakes $(2 \%$ (5) vs. $4 \%$ (9)). There were no obvious differences in the habitat composition variables between near and far plots (Mann-Whithey U-tests, two-tailed P $>0.25$ for each habitat type).

\section{Discussion}

Larders of pygmy owls were smaller in the plots with Tengmalm's owl boxes than in those without. Therefore, our results support the prediction of the interspecific food competition hypothesis (Korpimäki 1987). Moreover, our results were in disagreement with the prediction of Oksanen's (1983) hypothesis that food stores of pygmy owls should be larger in near than far plots.

We found that small-entrance nest-boxes near largeentrance ones contained lower numbers of cached prey items than small-entrance nest-boxes far from largeentrance ones. Therefore, we can exclude the possibility that avoidance of cache-robbing in large-entrance nestboxes would be the only reason for lower cache sizes in the plots with Tengmalm's owl boxes. Solheim (1984) found that pygmy owls preferred small-entrance nestboxes for caching. He suggested that pygmy owls avoided cache-robbers, such as Tengmalm's owls and pine martens Martes martes. However, he could not rule

Table 1. The mean number of prey items lardered in nest-boxes by pygmy owls in near plots with Tengmalm's owl boxes and far plots without Tengmalm's owl boxes. Pooled data from winters 1990-1991 and 1991-1992. U represents Mann-Whitney U-test, comparing the plots with low or high density of Tengmalm's owls and P is the probability level (two-tailed).

\begin{tabular}{|c|c|c|c|c|c|c|}
\hline \multirow[t]{2}{*}{ Prey species } & \multicolumn{2}{|c|}{ Far } & \multicolumn{2}{|c|}{ Near } & \multicolumn{2}{|c|}{ Test } \\
\hline & Mean & SD & Mean & SD & 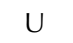 & $P$ \\
\hline Microtus voles* & 16.9 & 16.1 & 6.8 & 13.3 & 14 & 0.12 \\
\hline Bank vole Clethrionomys glareolus & 10.1 & 4.8 & 1.8 & 1.7 & 4.5 & 0.0015 \\
\hline Harvest mouse Micromys minutus & 7.6 & 14.2 & 0.0 & 0.0 & 12 & 0.073 \\
\hline Shrews (Sorex spp.) & 7.6 & 13.3 & 0.1 & 0.4 & 5.5 & 0.011 \\
\hline Number of plots with caches & 7 & & 8 & & & \\
\hline Total number of plots & 17 & & 19 & & & \\
\hline
\end{tabular}

*The field vole Microtus agrestis and the sibling vole M. rossiaemerionalis. 
out the possibility that competition for food from other predators would have been the reason, why pygmy owls cached lower prey numbers (usually one prey item) in large-entrance nest-boxes than small-entrance ones.

We suggest that pygmy owls made smaller larders in the near than in the far plots because of food competition by Tengmalm's owls (see also Korpimäki, 1987). Tengmalm's owls hunt in dense vole patches and are able to depress vole densities (Korpimäki and Norrdahl 1989b), in particular with other vole-eating avian and mammalian predators (Korpimäki et al. 2005). This may lower hunting success of pygmy owls and thus make them less able to larder. Alternatively, pygmy owls had to reduce foraging or to avoid best food patches when foraging under the Tengmalm's owl predation risk and this resulted in smaller larders. However, we found similar numbers of larders of pygmy owls in both near and far plots, and only the larder size was different. This supports the interpretation that pygmy owls can co-exist with larger owls, but the larder size is smaller because of higher competition for the non-renewable food resource during winter.

In this study, food competition between pygmy owls and the larger Tengmalm's owls seemed to be more important than predation risk in reducing food cache size of smaller allospecifics in late autumn and winter. Whether the competition for food with Tengmalm's owls and/or Tengmalm's owl predation risk lowers the reproductive success and survival of pygmy owls will be a challenge for future studies.

Acknowledgements - We are grateful to A. Sirkka, who made the nest-boxes used in this study, and to G. A. Sonerud for comments on the draft manuscript. Financial support was provided by the Academy of Finland (to J. Suhonen, E. Korpimäki and T. Mappes), by Emil Aaltonen Foundation (to J. Suhonen and M. Halonen), by Jenny and Antti Wihuri Foundation and the Cultural Foundation of Central Finland (to M. Halonen).

\section{References}

Connell, J. H. 1983. On the prevalence and relative importance of interspecific competition: evidence from field experiments. - Am. Nat. 122: 661-696.

Ekman, J. 1986. Tree use and predator vulnerability of wintering passerines. - Ornis Scand. 17: 261-267.

Gurevitch, J., Morrison, J. A. and Hedges, L. V. 2000. The interaction between competition and predation: a metaanalysis of field experiments. - Am. Nat. 155: 435-453.

Hakkarainen, H. and Korpimäki, E. 1996. Competitive and predatory interactions among raptors: an observational and experimetal study. - Ecology 77: 1134-1142.

Hakkarainen, H., Mykrä, S., Kurki, S., Korpimäki, E., Nikula, A. and Koivunen, V. 2003. Habitat composition as a determinant of reproductive success of Tengmalm's owls under fluctuating food conditions. - Oikos 100: $162-171$.

Halonen, M., Mappes, T., Meri, T. and Suhonen, J. 2007. Influence of snow cover on food hoarding in Pygmy Owls Glaucidium passerinum. - Ornis Fenn. 84: 000-000.

Kellomäki, E. 1977. Food of the pygmy owl Glaucidium passerinum in the breeding season. - Ornis Fenn. 54: $1-29$.

Korpimäki, E. 1981. On the ecology and biology of Tengmalm's owl (Aegolius funereus) in southern Ostrobothnia and Suomenselkä, western Finland. - Acta Universitatis Ouluensis A. Scientiae Rerum Naturalium No. 118 Biologica 13: 1-84.

Korpimäki, E. 1987. Prey caching of breeding Tengmalm's owls Aegolius funereus as a buffer against temporary food shortage. - Ibis 129: 499-510.

Korpimäki, E. 1988a. Diet of breeding Tengmalm's owls Aegolius funereus: long-term changes and year-to-year variation under cyclic food conditions. - Ornis Fenn. 65: $21-30$.

Korpimäki, E. 1988b. Effects of territory quality on occupancy, breeding performance and breeding dispersal in Tengmalm's owl. - J. Anim. Ecol. 57: 97-108.

Korpimäki, E. 1993. Does nest-hole quality, poor breeding success or food depletion drive the breeding dispersal of Tengmalm's owls? - J. Anim. Ecol. 62: 606-613.

Korpimäki, E. 1994. Rapid or delayed tracking of multiannual vole cycles by avian predators? - J. Anim. Ecol. 63: 619-628.

Korpimäki, E. and Norrdahl, K. 1989a. Avian predation on mustelids in Europe 1: occurrence and effects on body size variation and life traits. - Oikos 55: 205-215.

Korpimäki, E. and Norrdahl, K. 1989b. Predation of Tengmalm's owls: numerical responses, functional responses and dampening impact on population fluctuations of microtines. - Oikos 54: 154-164.

Korpimäki, E., Norrdahl, K., Huitu, O. and Klemola, T. 2005. Predator-induced synchrony in population oscillations of co-existing small mammal species. - Proceedings of the Royal Society of London B 272: 193-202.

Krüger, O. 2002. Interactions between common buzzards Buteo buteo and goshawk Accipiter gentilis: trade-offs revealed by a field experiment. - Oikos 96: 441-452.

Kullberg, C. 1995. Strategy of the pygmy owl while hunting avian and mammalian prey. - Ornis Fenn. 72: 72-78.

Lima, S. L. and Dill, L. M. 1990. Behavioral decisions made under the risk of predation: a review and prospectus. - Can. J. Zool. 68: 619-640.

Mikkola, H. 1983. Owls of Europe. - T. \& A. D. Poyser, Calton.

Oksanen, T. 1983. Prey caching in the hunting strategy of small mustelids. - Acta Zool. Fenn. 174: 197-199.

Palomares, F. and Caro, T. M. 1999. Interspecific killing among mammalian carnivores. - American Naturalist 153: 492-508.

Persson, L. 1985. Asymmetrical competition: are larger animals competitively superior? - American Naturalist 126: $261-266$. 
Polis, G. A., Myers, C. A. and Holt, R. D. 1989. The ecology of intraguild predation: potential competitors that eat each other. - Annu. Rev. Ecol. Syst. 20: 297-330.

Polis, G. A. and Holt, R. D. 1992. Intraguild predation: the dynamics of complex trophic interactions. - Trends Ecol. Evol. 7: 151-154.

Schoener, T. W. 1983. Field experiments on interspecific competition. - Am. Nat. 122: 240-285.

Schönn, S. 1980. Der Sperlingkauz.-Die Neue BrehmBücherei. - Wittenberg-Lutherstadt.

Sergio, F., Marchesi, L. and Pedrini, P. 2003. Spatial refugia and the coexistence of a diurnal raptor with its intraguild owl predator. - J. Anim. Ecol. 72: 232-245.
Sih, A., Crowley, P., McPeek, M., Petranka, J. and Strohmeier, K. 1985. Predation, competition and prey communities: a review of field experiments. - Annu. Rev. Ecol. Syst. 16: 269-311.

Solheim, R. 1984. Caching behavior, prey choice and surplus killing by pygmy owls Glaucidium passerinum during winter, a functional response of a generalist predator. - Ann. Zool. Fenn. 21: 301-308.

Suhonen, J. 1993. Predation risk influences the use of foraging sites by tits. - Ecology 74: 1197-1203.

Wiens, J. A. 1989. The ecology of bird communities. Vol 2. Processes and variations. - Cambridge Univiversity Press, Cambridge. 